Jurnal Keperawatan Silampari

Volume 4, Nomor 2, Juni 2021

e-ISSN: 2581-1975

p-ISSN: 2597-7482

DOI: https://doi.org/10.31539/jks.v4i2.1817

\title{
PENGEMBANGAN FORMAT DOKUMENTASI ASUHAN KEPERAWATAN GAWAT DARURAT BERBASIS SDKI, SLKI, DAN SIKI
}

\author{
Nelly Hermala Dewi ${ }^{1}$, Eti Suryati ${ }^{2}$, Fertin Mulyanasari ${ }^{3}$, \\ Lisnawati Yupartini ${ }^{4}$ \\ Universitas Sultan Ageng Tirtayasa ${ }^{1,2,3,4}$ \\ nelly.hd@untirta.ac.id ${ }^{1}$
}

\begin{abstract}
ABSTRAK
Penelitian ini bertujuan untuk mengetahui pengembangan format dokumentasi asuhan keperawatan gawat darurat berbasis SDKI, SLKI, dan SIKI, mutu pengembangan format, dan mutu dokumentasi pengembangan format tersebut di Ruang Gawat Darurat RSUD Dradjat Prawiranegara Serang Banten. Metode penelitian yaitu research and development. Hasil penelitian ini adalah ditetapkan diagnosis keperawatan yang sesuai dengan pengkajian primer, mutu pengembangan format dokumentasi asuhan keperawatan gawat darurat secara functionaly, efficiency, dan usability baik. Mutu dokumentasi asuhan keperawatan gawat darurat meliputi kelengkapan, akurasi, relevansi, dan kebaruan baik. Simpulan, format dokumentasi asuhan keperawatan berbasis SDKI, SLKI, SIKI dapat digunakan di ruang gawat darurat untuk meningkatkan kualitas asuhan keperawatan.
\end{abstract}

Kata Kunci : Dokumentasi Asuhan Keperawatan Gawat Darurat, SDKI, SLKI, SIKI

\section{ABSTRACT}

This study aims to determine the development of the emergency nursing care documentation format based on the IDHS, SLKI, and SIKI, the quality of the format development, and the quality of the documentation for the development of the design in the Emergency Room of Dradjat Prawiranegara Hospital Serang Banten. The research method is Research and Development. The result of this research is that the nursing diagnosis is determined according to the primary assessment. The quality of developing the emergency nursing care documentation format is functional, efficient, and usable. And the quality of emergency nursing care documentation includes completeness, accuracy, relevance, and good novelty. In conclusion, the format of nursing care documentation based on IDHS, SLKI, SIKI can be used in the emergency room to improve the quality of nursing care.

Keywords: Documentation of Emergency Nursing Care, IDHS, SLKI, SIKI

\section{PENDAHULUAN}

Pelayanan keperawatan gawat darurat sangat vital di rumah sakit, karena pelayanan tersebut bertujuan untuk menyelamatkan nyawa dan meminimalkan kecatatan yang terjadi pada pasien. Pelayanan gawat darurat meliputi tindakan medis yang diberikan pasien yang berada dalam ancaman kematian dan kecacatan yang memerlukan tindakan medis segera untuk menyelamatkan nyawa dan pencegahan kecatatan. Kondisi kegawatan dapat terjadi 
dimana saja sehingga menjadikan perawat sebagai bagian dari tim kesehatan harus siap mengadakan asuhan gawat darurat. Asuhan keperawatan gawat darurat yang dilakukan di ruang gawat darurat harus dilakukan secara sistematis, cepat, tepat, dan akurat agar keadaan pasien selamat dan stabil, serta didukung oleh sarana dan prasarana dan sistem kerja efisien dan efktif, diantaranya dengan penggunaan dokumentasi asuhan keperawatan gawat darurat sebagai salah satu bentuk komunikasi perawat (PPNI, 2017; PPNI, 2019; PPNI, 2018; Vafaei et al., 2018).

Pelayanan kegawatdaruratan diberikan kepada pasien yang mengancam nyawa, membahayakan diri dan lingkungannya, meliputi sumbatan jalan napas, pernapasan, dan sirkulasi, adanya penurunan kesadaran, adanya gangguan hemodinamik, dan adanya yang memerlukan tindakan segera (Permenkes No 47 Thn 2018 Tentang Pelayanan Kegawat Daruratan, 2018). Asuhan keperawatan gawat darurat yang harus dilaksanakan di ruang gawat darurat meliputi tiase, pengkajian secara primer dan sekunder. Pengkajian primer pada pasien trauma meliputi airway, breathing, circulation, disability, dan exposure. Pengkajian pada pasien non trauma meliputi meliputi airway, breathing, circulation, defibrillation/ drugs, differential diagnosis, dan electrolyte imbalance, dan pengkajian sekunder meliputi head to toe, dilanjutkan retriase, penentuan diagnosis keperawatan, penentuan intervensi, implementasi, dan evaluasi (Vafaei et al., 2018; Frink et al., 2017).

Untuk melaksanakan pelayanan kegawatdaruratan, praktik keperawatan harus didasarkan pada kode etik, standar pelayananan, standar profesi, dan standar prosedur operasional yang sesuai dengan pasal 28 Undang-Undang No. 38 Tahun 2014 tentang Keperawatan yang telah disusun oleh organisisai Persatuan Perawat Nasional Indonesia (PPNI). Standar yang dimaksud meliputi Standar Diagnosis Keperawatan Indonesia (SDKI), Standar Luaran Keperawatan Indonesia (SLKI), Standar Intervensi Keperawatan Indonesia (SIKI). Pelayanan keperawatan gawat darurat memerlukan penanganan secara terpadu dari multi disiplin dan multi profesi (PPNI, 2017; PPNI, 2019; PPNI, 2018).

Pelayanan profesional keperawatan memiliki metodologi yang menjamin tercapainya tujuan dengan optimal dan dapat dipertanggung-jawabkan secara moral dan hukum, metode itu adalah proses keperawatan. Proses keperawatan merupakan inti praktik keperawatan dan sekaligus isi pokok dokumentasi keperawatan. Pengelompokan dokumentasi keperawatan mengikuti tahapan proses keperawatan yaitu pengkajian, diagnosis keperawatan, perencanaan, tindakan, dan evaluasi keperawatan yang disusun secara sistematis, valid, dan dapat dipertanggung jawabkan secara hukum dan moral (Tajabadi et al., 2020).

Sejalan dengan perkembangan ilmu dan teknologi saat ini perawat sebagai pemberi jasa pelayanan kesehatan dituntut untuk selalu meningkatkan pengetahuan dan keterampilan dalam melakukan dokumentasi keperawatan, yang terdiri dari diagnosis keperawatan, luaran keperawatan, dan intervensi keperawatan (Ioanna et al., 2017).

Diagnosis keperawatan merupakan penilaian klinis terhadap pengalaman atau respon individu, keluarga, atau komunitas pada masalah kesehatan, pada risiko masalah kesehatan atau pada proses kehidupan. Diagnosis keperawatan merupakan bagian vital dalam menentukan asuhan keperawatan yang sesuai untuk membantu klien mencapai derajat kesehatan yang optimal (PPNI, 2017; Asmirajanti et al., 2019; Kamil et al., 2018). Luaran keperawatan akan menjadi acuan bagi perawat dalam menetapkan kondisi atau status kesehatan seoptimal mungkin yang diharapkan dapat dicapai oleh klien setelah pemberian intervensi keperawatan (PPNI, 2019; Akhu-Zaheya et al., 2018). Intervensi keperawatan merupakan segala bentuk terapi yang dikerjakan perawat yang didasarkan pada pengetahuan dan penilaian klinis untuk mencapai peningkatan, pencegahan, dan pemulihan kesehatan klien individu, keluarga, dan komunitas (PPNI, 2018; Akhu-Zaheya et al., 2018). 
Rumah Sakit Umum Daerah (RSUD) Dradjat Prawiranegara merupakan salah satu rumah sakit rujukan di Provinsi Banten. Pasien yang datang ke ruang gawat darurat rumah sakit ini dengan tingkat keparahan yang beragam. Di ruang Gawat Darurat RSUD Dradjat Prawiranegara Serang Banten saat ini telah menggunakan format asuhan keperawatangawat darurat, namun belum berbasis SDKI, SLKI, dan SIKI. Fokus penanganan masalah di ruang gawat darurat untuk menyelamatkan nyawa, stabilisasi pasien, dan meminimalkan kecacatan yang terjadi pada pasien. Keadaan tersebut membuat asuhan keperawatan gawat darurat yang dilakukan belum terdokumentasi secara mutakhir mengikuti perkembangan dokumentasi asuhan keperawatan yang sesuai dengan organisasi profesi PPNI Indonesia. Format asuhan keperawatan berbasis SDKI, SLKI, dan SIKI sangat dibutuhkan untuk memudahkan perawat dalam mendokumentasikan asuhan keperawatan gawat darurat yang mengikuti perkembangan IPTEK keperawatan, sehingga pelayanan pasien gawat darurat dilaksanakan secara efektif dan efesien.

\section{METODE PENELITIAN}

Metode yang digunakan dalam penelitian ini adalah metode penelitian dan pengembangan atau research and development, yaitu untuk menghasilkan produk tertentu dan menguji keefektifan produk tersebut. Produk baru yaitu format dokumentasi asuhan keperawatan gawat darurat yang berbasis SDKI, SLKI, dan SIKI. Untuk dapat menghasilkan produk ini dibutuhkan penelitian yang bersifat analisis yaitu melalui focus group discussion, dan untuk mengetahui keefektifan produk ini dilakukan uji coba oleh perawat ruang gawat darurat dan penilaian komite keperawatan RSUD Dradjat Prawiranegara Serang Banten, jadi penelitian dan pengembangan bersifat longitudinal/ bertahap.

Penelitian ini telah dilaksanakan sejak April s.d. November 2020 di ruang IGD RSUD Dradjat Prawiranegara Serang Banten, dengan sampel 31 orang perawat IGD dan 10 anggota komite keperawatan RSUD Dradjat Prawiranegara Serang Banten. Alat pengumpulan data yang telah digunakan adalah kuisioner dan lembar observasi. Kuisioner terdiri dari Efficiency dan Usability pengembangan format dokumentasi asuhan keperawatan gawat darurat. Lembar observasi digiunakan untuk menilai mutu dokumentasi pengembangan format Asuhan keperawatan gawat darurat berdasarkan SDKI, SLKI, dan SIKI.

\section{HASIL PENELITIAN}

Tabel. 1

Rencana Asuhan Keperawatan Gawat Darurat Berdasarkan SDKI, SLKI, dan SIKI

\begin{tabular}{|c|c|c|c|}
\hline Data & $\begin{array}{c}\text { Diagnosis } \\
\text { Keperawatan }\end{array}$ & Luaran Keperawatan & $\begin{array}{c}\text { Intervensi } \\
\text { Keperawatan }\end{array}$ \\
\hline \multicolumn{4}{|c|}{ Jalan napas/ Airway } \\
\hline $\begin{array}{l}\text { Objektif } \\
\text { Batuk tidak efektif } \\
\text { Tidak mampu } \\
\text { batuk } \\
\text { Sputum berlebih } \\
\text { Mengi, wheezing } \\
\text { dan/atau ronkhi } \\
\text { kering }\end{array}$ & $\begin{array}{l}\text { Bersihan jalan } \\
\text { napas tidak } \\
\text { efektif }\end{array}$ & $\begin{array}{l}\text { Bersihan jalan napas } \\
\text { meningkat, } \\
\text { kriteria hasil } \\
\text { Batuk efektif meningkat } \\
\text { wheezing dan/atau ronkhi } \\
\text { kering menurun } \\
\text { Meconium di jalan napas } \\
\text { (pada bayi) menurun }\end{array}$ & $\begin{array}{l}\text { Insersi jalan napas } \\
\text { Manajemen asma } \\
\text { Manajemen jalan } \\
\text { napas buatan } \\
\text { Penghisapan jalan } \\
\text { napas } \\
\text { Pencegahan aspirasi } \\
\text { Latihan batuk }\end{array}$ \\
\hline
\end{tabular}




\begin{tabular}{|c|c|c|c|}
\hline $\begin{array}{l}\text { Meconium di jalan } \\
\text { napas (pada bayi) }\end{array}$ & & & $\begin{array}{l}\text { efektif } \\
\text { Pengaturan posisi } \\
\text { Terapi oksigen }\end{array}$ \\
\hline \multicolumn{4}{|l|}{ Pernapasan/ Breathing } \\
\hline $\begin{array}{l}\text { Subjektif } \\
\text { Dipsnea } \\
\text { Objektif } \\
\text { Penggunaan otot } \\
\text { bantu pernapasan } \\
\text { Fase ekspirasi } \\
\text { memanjang, } \\
\text { Inspirasi:ekspirasi = } \\
\ldots \ldots . \text { detik : ..... } \\
\text { detik } \\
\text { Pola napas } \\
\text { abnormal, kusmaul, } \\
\text { cheyne stokes }\end{array}$ & $\begin{array}{l}\text { Pola napas } \\
\text { tidak efektif }\end{array}$ & $\begin{array}{l}\text { Pola napas membaik, } \\
\text { kriteria hasil : } \\
\text { Dipsnea menurun } \\
\text { Penggunaan otot bantu } \\
\text { napas menurun } \\
\text { Pernapasan cuping hidung } \\
\text { menurun } \\
\text { Frekuensi napas membaik } \\
\text { Saturasi oksigen meningkat }\end{array}$ & $\begin{array}{l}\text { Pemantauan } \\
\text { respirasi } \\
\text { Terapi oksigen } \\
\text { Dukungan ventikasi } \\
\text { Manajemen } \\
\text { ventilasi mekanik } \\
\text { Manajemen jalan } \\
\text { napas }\end{array}$ \\
\hline $\begin{array}{l}\text { Mayor } \\
\text { Subjektif } \\
\text { Dipsnea } \\
\text { Objektif } \\
\text { PCO2 } \\
\text { meningkat/menuru } \\
\text { n, nilai PCO2 } \\
\ldots \ldots . . . . \\
\text { PO2 menurun, nilai } \\
\text { PO2............. } \\
\text { Takikardia, nadi } \\
\ldots \ldots . . x / \text { menit } \\
\text { pH arteri Bunyi } \\
\text { napas tambahan, } \\
\text { bunyi napas } \\
\text { tambahan: snoring, } \\
\text { stridor, crowing, } \\
\text { rochi, wheezing, } \\
\text { gurgling }\end{array}$ & $\begin{array}{l}\text { Gangguan } \\
\text { pertukaran } \\
\text { gas }\end{array}$ & $\begin{array}{l}\text { Pertukaran gas meningkat } \\
\text { Kritria hasil : } \\
\text { Tingkat kesadaran } \\
\text { meningkat } \\
\text { Dyspnea menurun } \\
\text { Gelisah menurun } \\
\text { Nafas cuping hidung } \\
\text { menurun } \\
\text { PCO2 membaik } \\
\text { PO2 membaik } \\
\text { Takikardia membaik } \\
\text { PH arteri membaik } \\
\text { Sianosis membaik } \\
\text { Pola nafas membaik }\end{array}$ & \\
\hline $\begin{array}{l}\text { Subjektif } \\
\text { dispneu } \\
\text { Objektif } \\
\text { penggunaan otot } \\
\text { bantu nafas } \\
\text { meningkat } \\
\text { volume tidal } \\
\text { menurun } \\
\text { pco2 meningkat } \\
\text { po2 menurun } \\
\text { SAO2 menurun }\end{array}$ & $\begin{array}{l}\text { Gangguan } \\
\text { ventilasi } \\
\text { spontan }\end{array}$ & $\begin{array}{l}\text { Ventilasi spontan meningkat } \\
\text { Kriteria hasil : } \\
\text { Volume tidal meningkat } \\
\text { Dispnea menurun } \\
\text { Penggunaan otot bantu } \\
\text { menurun } \\
\text { Gelisah meurun } \\
\text { PCO2 membaik } \\
\text { PO2 membaik } \\
\text { Takikardia membaik }\end{array}$ & \\
\hline \multicolumn{4}{|l|}{ Sirkulasi/ Circulation } \\
\hline $\begin{array}{l}\text { Subjektif } \\
\text { Ortopnea } \\
\text { Dispnea } \\
\text { Paroxysmal } \\
\text { nocturnal dyspnea } \\
\text { (PND) } \\
\text { Objektif } \\
\text { Edema anasarka }\end{array}$ & Hipervolemia & $\begin{array}{l}\text { Keseimbangan cairan } \\
\text { meningkat } \\
\text { Kriteria hasil : } \\
\text { Haluaran urin meningkat } \\
\text { Kelembapan membrane } \\
\text { mukosa meningkat } \\
\text { Edema menurun } \\
\text { Tekanan darah membaik }\end{array}$ & $\begin{array}{l}\text { Insersi intravena } \\
\text { Manajemen aritmia } \\
\text { Manajemen } \\
\text { defibrilasi } \\
\text { Manajemen } \\
\text { perdarahan } \\
\text { Resusitasi cairan } \\
\text { Manajemen syok }\end{array}$ \\
\hline
\end{tabular}




\begin{tabular}{|c|c|c|c|}
\hline $\begin{array}{l}\text { dan/atau edema } \\
\text { perifer } \\
\text { Berat badan } \\
\text { meningkat dalam } \\
\text { waktu singkat } \\
\text { Jugular Venous } \\
\text { Pressure } \\
\text { (JVP)/atau Cental } \\
\text { Venous Pressure } \\
\text { (CVP) }\end{array}$ & & $\begin{array}{l}\text { Denyut nadi radial membaik } \\
\text { Tekanan arteri rata-rata } \\
\text { membaik } \\
\text { Jugular veneous Pressure } \\
\text { (JPV) membaik }\end{array}$ & $\begin{array}{l}\text { Transfusi darah } \\
\text { Manajemen asam- } \\
\text { basa } \\
\text { Resusitasi jantung } \\
\text { paru }\end{array}$ \\
\hline $\begin{array}{l}\text { Subjektif } \\
\text { Tidak tersedia } \\
\text { Objektif } \\
\text { Frekuensi nadi } \\
\text { meningkat } \\
\text { Nadi terasa lemah } \\
\text { Tekanan darah } \\
\text { menurun } \\
\text { Turgor kulit } \\
\text { menurun } \\
\text { Membrane mukosa } \\
\text { kering } \\
\text { Volume urine } \\
\text { menurun } \\
\text { Hematokrtit } \\
\text { meningkat }\end{array}$ & Hipovolemia & $\begin{array}{l}\text { Status cairan membaik } \\
\text { Kriteria hasil : } \\
\text { Kekuatan nadi meningkat } \\
\text { Membrane mukosa lembab } \\
\text { meningkat } \\
\text { Output urine meningkat } \\
\text { Tekanan darah membaik } \\
\text { Tekanann nadi membaik } \\
\text { Membrane mukosa } \\
\text { membaik } \\
\text { Kadar Hb, HT membaik } \\
\text { Status mental membaik } \\
\text { Suhu tubuh membaik }\end{array}$ & \\
\hline $\begin{array}{l}\text { Subjektif } \\
\text { Palpitasi } \\
\text { Ortopnea } \\
\text { Batuk } \\
\text { Objektif } \\
\text { Perubahan Irama } \\
\text { Jantung } \\
\text { Bradikardia / } \\
\text { Takikardia } \\
\text { Gambaran EKG } \\
\text { Aritmia Atau } \\
\text { Edema } \\
\text { Distensi Vena } \\
\text { Jugularis } \\
\text { Central Venous } \\
\text { Pressure ( CVP ) } \\
\text { Meningkat/ } \\
\text { Menurun } \\
\text { Tekanan Darah } \\
\text { Meningkat/ } \\
\text { Menurun } \\
\text { Nadi Periper } \\
\text { Teraba Lemah } \\
\text { Cappilary Refill } \\
\text { Time > } 3 \text { Detik } \\
\text { Oliguria } \\
\text { Warna Kulit Pucat } \\
\text { Dan Atau Sianosis }\end{array}$ & $\begin{array}{l}\text { Penurunan } \\
\text { curah jantung }\end{array}$ & $\begin{array}{l}\text { Curah jantung meningkat } \\
\text { Kriteria hasil : } \\
\text { Kekuatan nadi perifer } \\
\text { meningkat } \\
\text { Palpitasi menurun } \\
\text { Bradikardia menurun } \\
\text { Takikardia menurun } \\
\text { Gambaran EKG aritmia } \\
\text { menurun } \\
\text { Lelah menurun } \\
\text { Edema menurun } \\
\text { Dyspnea menurun } \\
\text { Oliguria menurun } \\
\text { Sianosis menurun } \\
\text { Paroxysmal nocturnal } \\
\text { dyspnea menurun } \\
\text { Ortopnea menurun } \\
\text { CRT membaik } \\
\text { Cntral veneous pressure } \\
\text { membaik }\end{array}$ & \\
\hline
\end{tabular}




\begin{tabular}{|c|c|c|c|}
\hline $\begin{array}{l}\text { Subjektif } \\
\text { Tidak tersedia } \\
\text { Objektif } \\
\text { Frekuensi nadi <50 } \\
\text { x/menit atau > } \\
150 x / \text { menit } \\
\text { Tekanan darah } \\
\text { sistolik <60mmhg } \\
\text { atau > 200mmhg } \\
\text { Frekuensi nafas } \\
<6 \mathrm{x} / \text { menit atau } \\
>30 \mathrm{x} / \text { menit }\end{array}$ & $\begin{array}{l}\text { Gangguan } \\
\text { sirkuasi } \\
\text { spontan }\end{array}$ & $\begin{array}{l}\text { Sirkulasi spontan meningkat } \\
\text { Kriteria hasil : } \\
\text { Tingkat kesadaran } \\
\text { meningkat } \\
\text { Frekuensi nadi menurun } \\
\text { Tekanan darah menurun } \\
\text { Frekuensi napas menurun } \\
\text { Suhu tubuh menurun } \\
\text { Saturasi oksigen menurun } \\
\text { Gambaran EKG aritmia } \\
\text { menurun } \\
\text { Produksi urine menurun }\end{array}$ & \\
\hline $\begin{array}{l}\text { Subjektif } \\
\text { Tidak tersedia } \\
\text { Objektif } \\
\text { Pengisiankapiler>3 } \\
\text { detik } \\
\text { Nadi perifer } \\
\text { menurun atau tidak } \\
\text { teraba } \\
\text { Akral teraba dingin } \\
\text { Warna kulit pucat } \\
\text { Turgor kulit } \\
\text { menurun }\end{array}$ & $\begin{array}{l}\text { Perfusi perifer } \\
\text { tidak efektif }\end{array}$ & $\begin{array}{l}\text { Perfusi perifer meningkat } \\
\text { Kriteria hasil : } \\
\text { Denyut nadi perifer } \\
\text { meningkat } \\
\text { Warna kulit pucat menurun } \\
\text { Akral membaik } \\
\text { Tekanan darah sistolik } \\
\text { membaik } \\
\text { Tekanan darah disastolik } \\
\text { membaik } \\
\text { Tekanan arteri rata-rata } \\
\text { membaik }\end{array}$ & \\
\hline $\begin{array}{l}\text { Subjektif } \\
\text { Sakit kepala } \\
\text { Objektif } \\
\text { Tekanan darah } \\
\text { meningkat dengan } \\
\text { tekanan nadi (pulse } \\
\text { pressure) melebar } \\
\text { Bradikardia } \\
\text { Pola napas irreguler } \\
\text { Tingkat kesadaran } \\
\text { menurun } \\
\text { Respon pupil } \\
\text { melambat atau } \\
\text { tidak sama } \\
\text { Refleks neurologis } \\
\text { terganggu }\end{array}$ & $\begin{array}{l}\text { Penurunan } \\
\text { kapasitas } \\
\text { adaptif } \\
\text { intrakranial }\end{array}$ & $\begin{array}{l}\text { Kapasitas adaptif } \\
\text { intracranial meningkat } \\
\text { Kriteria hasil : } \\
\text { Tingkat kesadaran meingkat } \\
\text { GCS..... } \\
\text { Muntah menurun } \\
\text { Postur deserebrasi (ekstensi } \\
\text { ) menurun } \\
\text { Tekanan darah membaik } \\
\text { Tekanan nadi membaik } \\
\text { Bradikardia membaik } \\
\text { Pola napas membaik } \\
\text { Respon pupil membaik } \\
\text { Refleks neurologis } \\
\text { membaik }\end{array}$ & $\begin{array}{l}\text { Pemantauan } \\
\text { neurologis } \\
\text { Manajemen kejang } \\
\text { Manajemen } \\
\text { peningkatan } \\
\text { tekanan intra kranial }\end{array}$ \\
\hline $\begin{array}{l}\text { Subjektif } \\
\text { Mengeluh nyeri } \\
\text { Skala nyeri:... } \\
\text { FLCC Behavioral } \\
\text { Pain Scale untuk } \\
\text { usia kurang dari } 3 \\
\text { tahun } \\
\text { Baker-Wong- } \\
\text { FACES scale untuk } \\
\text { usia 3-7 tahun } \\
\text { Visual analog } \\
\text { scale/ numeric } \\
\text { scale untuk usia di } \\
\text { atas } 7 \text { tahun } \\
\text { Objektif } \\
\text { Nampak meringis }\end{array}$ & Nyeri akut & $\begin{array}{l}\text { Tingkat nyeri menurun } \\
\text { Kriteria Hasil : } \\
\text { Kemampuan menuntaskan } \\
\text { aktivitas meningkat } \\
\text { Keluhan nyeri menurun } \\
\text { Meringis menurun } \\
\text { Gelisah menurun } \\
\text { Kesulitan tidur menurun } \\
\text { Diaphoresis menurun } \\
\text { Frekuensi nadi membaik } \\
\text { Pola nafas membaik } \\
\text { Tekanan darah membaik } \\
\text { Proses berpikir membaik }\end{array}$ & $\begin{array}{l}\text { Manajemen nyeri } \\
\text { Balut tekan } \\
\text { Pembidaian } \\
\text { Perawatan luka } \\
\text { Penjahitan luka }\end{array}$ \\
\hline
\end{tabular}




\begin{tabular}{lll}
\hline $\begin{array}{l}\text { Bersikap protektif } \\
\text { Gelisah } \\
\text { Frekuensi nadi } \\
\text { meningkat }\end{array}$ & \\
Sulit tidur & & \\
\hline $\begin{array}{l}\text { Subjektif } \\
\text { (Tidak Tersedia) }\end{array}$ & $\begin{array}{l}\text { Gangguan } \\
\text { integritas } \\
\text { jaringan } \\
\text { (kulit, }\end{array}$ & $\begin{array}{l}\text { Integritas kulit dan jaringan } \\
\text { meningkat }\end{array}$ \\
Objektif & Kriteria hasil : \\
Kerusakan & Elastisitas meningkat \\
jaringan/ lapisan & tulang) & Hidrasi meningkat \\
kulit & & Perfusi jaringan meningkat \\
& & Kerusakan jaringan \\
menurun \\
& & Kerusakan lapisan kulit \\
& & menurun \\
& & Nyeri menurun \\
& & Perdarahan menurun \\
& & Kemerahan menurun \\
& & Hematoma menurun \\
& & Pigmentasi abnormal \\
& menurun \\
& & Jaringan perut menurun \\
& Nekrosis menurun \\
\hline &
\end{tabular}

Berdasarkan tabel 1 menunjukkan bahwa pengembangan format asuhan keperawatan darurat berbasis SDKI, SLKI, dan SIKI berdasarkan pengkajian primer airway, breathing, circulation, disability, dan exposure, format meliputi pengkajian, diagnosis keperawatan, luaran keperawatan, dan intervensi keperawatan, format ini dapat diisi dengan menandai (checklist) data sesuai dengan kondisi pasien.

\section{Mutu Pengembangan Format Dokumentasi Asuhan Keperawatan Gawat Darurat Berbasis SDKI, SLKI, dan SIKI \\ Functionality}

Tabel. 2

Distribusi Frekuensi Functionality Pengembangan Format Dokumentasi Asuhan Keperawatan Gawat Darurat Berbasis SDKI, SLKI, dan SIKI $(n=10)$

\begin{tabular}{lcccc}
\hline \multirow{2}{*}{ Format dokumentasi } & \multicolumn{4}{c}{ Kriteria } \\
\cline { 2 - 5 } & \multicolumn{2}{c}{ Baik } & \multicolumn{2}{c}{ Sedang } \\
\cline { 2 - 5 } & Frekuensi & Presentase \% & Frekuensi & Presentase \% \\
\hline Pengkajian primer & 9 & 90 & 1 & 10 \\
Diagnosis & 10 & 100 & 0 & 0 \\
Luaran & 9 & 90 & 1 & 10 \\
Intervensi & 8 & 80 & 2 & 20 \\
Implementasi & 9 & 90 & 1 & 10 \\
Evaluasi & 8 & 80 & 2 & 20 \\
\hline
\end{tabular}

Berdasarkan tabel 2 menunjukkan bahwa dari total 10 responden yang diteliti hampir seluruhnya menyatakan bahwa pengembangan format dokumentasi asuhan keperawatan gawat darurat berbasis SDKI, SLKI, dan SIKI dapat berfungsi baik. 


\section{Efficiency dan Usability}

Tabel. 3

Distribusi Frekuensi Efficiency dan Usability Pengembangan Format Dokumentasi Asuhan Keperawatan Gawat Darurat Berbasis SDKI, SLKI, dan SIKI $(n=31)$

\begin{tabular}{lcccc}
\hline & \multicolumn{4}{c}{ Kriteria } \\
\cline { 2 - 5 } \multicolumn{1}{c}{ Format Dokumentasi } & \multicolumn{2}{c}{ Baik } & \multicolumn{2}{c}{ Kurang baik } \\
\cline { 2 - 5 } & Frekuensi & $\begin{array}{c}\text { Presentase } \\
\%\end{array}$ & Frekuensi & Presentase\% \\
\hline Pengkajian primer & 29 & 93,5 & 2 & 6,5 \\
Diagnosis & 30 & 96,8 & 1 & 3,2 \\
Luaran & 28 & 90,3 & 3 & 9,7 \\
Intervensi & 29 & 93,5 & 2 & 6,5 \\
Implementasi & 30 & 96,8 & 1 & 3,2 \\
Evaluasi & 30 & 96,8 & 1 & 3,2 \\
\hline
\end{tabular}

Berdasarkan tabel 3 menunjukkan bahwa dari total 31 responden yang diteliti diketahui hampir seluruhnya efficiency dan usability pengembangan format dokumentasi asuhan keperawatan gawat darurat berbasis SDKI, SLKI, dan SIKI adalah baik.

\section{Mutu Dokumentasi Asuhan Keperawatan Gawat Darurat Berbasis SDKI, SLKI, dan SIKI}

Tabel. 4

Distribusi Frekuensi Mutu Dokumentasi Asuhan Keperawatan Gawat Darurat Berbasis SDKI, SLKI, dan SIKI ( $\mathrm{n}=31)$

\begin{tabular}{clcccc}
\hline \multirow{2}{*}{$\begin{array}{c}\text { Parameter } \\
\text { Mutu }\end{array}$} & Dokumentasi & \multicolumn{4}{c}{ Katagori } \\
\cline { 3 - 6 } & Keperawatan & \multicolumn{3}{c}{ Sedang } & \multicolumn{3}{c}{ Baik } \\
\cline { 3 - 6 } Kelengkapan & Pengkajian & 1 & 3,2 & 30 & 96,8 \\
& Diagnosis & 1 & 3,2 & 30 & 96,8 \\
& Luaran & 3 & 9,7 & 28 & 90,3 \\
& Intervensi & 2 & 6,5 & 29 & 93,5 \\
& Implementasi & 3 & 9,7 & 28 & 90,3 \\
& Evaluasi & 3 & 9,7 & 28 & 90,3 \\
\hline Akurasi & Pengkajian & 2 & 6,5 & 29 & 93,5 \\
& Diagnosis & 2 & 6,5 & 29 & 93,5 \\
& Luaran & 3 & 9,7 & 28 & 90,3 \\
& Intervensi & 2 & 6,5 & 29 & 93,5 \\
& Implementasi & 4 & 12,9 & 27 & 87,1 \\
& Evaluasi & 4 & 12,9 & 27 & 87,1 \\
& & & & & \\
\hline Relevansi & Pengkajian & 2 & 6,5 & 29 & 93,5 \\
& Diagnosis & 0 & 0 & 31 & 100 \\
& Luaran & 2 & 6,5 & 29 & 93,5 \\
& Intervensi & 4 & 12,9 & 27 & 87,1 \\
& Implementasi & 3 & 9,7 & 28 & 90,3 \\
& Evaluasi & 2 & 6,5 & 29 & 93,5 \\
\hline Kebaruan & Pengkajian & 3 & 9,7 & 28 & 90,3 \\
& Diagnosis & 2 & 6,5 & 29 & 93,5 \\
& Luaran & 2 & 6,5 & 29 & 93,5 \\
& Intervensi & 2 & 6,5 & 29 & 93,5 \\
& Implementasi & 2 & 6,5 & 29 & 93,5 \\
& Evaluasi & 2 & 6,5 & 29 & 93,5 \\
\hline
\end{tabular}


Berdasarkan tabel 4 menunjukkan bahwa dari bahwa dari total 31 responden yang diteliti diketahui hampir seluruhnya mutu pengembangan format dokumentasi asuhan keperawatan gawat darurat berbasis SDKI, SLKI, dan SIKI berdasar kelengkapan, akurasi, relevansi, dan kebaruan adalah baik.

\section{PEMBAHASAN \\ Pengembangan Format Dokumentasi Asuhan Keperawatan Gawat Darurat Berbasis SDKI, SLKI, dan SIKI}

Asuhan keperawatan adalah praktik keperawatan baik secara langsung atau tidak langsung yang diberikan kepada klien, keluarga, dan masyarakat dengan menggunakan pendekatan ilmiah berdasarkan kode etik dan standar praktek keperawatan (Kebede et al., 2017). Pelayanan kegawatdaruratan diberikan kepada pasien yang mengancam nyawa, mebahayakan diri dan lingkungannya, adanya gangguan pada jalan napas, pernapasan, dan sirkulasi, adanya penurunan kesadaran, adanya gangguan hemodinamik, dan adanya yang memerlukan tindakan segera (Permenkes No 47 Thn 2018 Tentang Pelayanan Kegawat Daruratan, 2018). Proses keperawatan merupakan inti praktik keperawatan dan sekaligus isi pokok dokumentasi keperawatan. Pengelompokan dokumentasi keperawatan mengikuti tahapan proses keperawatan yaitu pengkajian, diagnosis keperawatan, perencanaan, tindakan, dan evaluasi keperawatan yang disusun secara sistematis, valid, dan dapat dipertanggung jawabkan secara hukum dan moral (Akhu-Zaheya et al., 2018; Bond et al., 2018).

Tujuan dokumentasi keperawatan adalah menjadi panduan atau acuan bagi perawat dalam melaksanakan pelayanan asuhan keperawatan, memenuhi aspek legal tanggung gugat dan tanggung jawab, meningkatkan otonomi perawat dalam memberikan pelayanan kesehatan, memudahkan komunikasi intraprofesional dan interprofesional, dan meningkatkan mutu asuhan keperawatan (PPNI, 2017). Pengkajian keperawatan adalah proses pengumpulan data primer dan sekunder berfokus pada status kesehatan pasien gawat darurat di rumah sakit secara sistematik, akurat, dan berkesinambungan untuk menetapkan masalah kegawatdaruratan pasien dan rencana tindakan cepat, tepat, dan cermat sesuai standar. Pengkajian secara primer dan sekunder. Pengkajian primer pada pasien trauma meliputi airway, breathing, circulation, disability, dan exposure. Pengkajian pada pasien non trauma meliputi meliputi airway, breathing, circulation, defibrillation/ drugs, differential diagnosis, dan electrolyte imbalance, dan pengkajian sekunder meliputi head to toe (McCarthy et al., 2019; Pitcher et al., 2017).

Diagnosis keperawatan merupakan penilaian klinis terhadap pengalaman atau respon individu, keluarga, atau komunitas pada masalah kesehatan, pada risiko masalah kesehatan atau pada proses kehidupan. Diagnosis keperawatan merupakan bagian vital dalam menentukan asuhan keperawatan yang sesuai untuk membantu klien mencapai derajat kesehatan yang optimal (PPNI, 2017). Diagnosis keperawatan gawat darurat atau masalah keperawatan gawat darurat merupakan keputusan klinis perawat tentang respon pasien terhadap masalah aktual maupun risiko yang mengancam jiwa. Masalah keperawatan yang ditegakkan merupakan dasar penyusunan rencana keperawatan dalam penyelamatan jiwa dan mencegah kecacatan (Platts-Mills et al., 2017).

Perencanaan keperawatan merupakan serangkaian langkah yang bertujuan untuk menyelesaikan masalah/ diagnosis keperawatan gawat darurat berdasarkan prioritas masalah yang telah ditetapkan baik secara mandiri maupun melibatkan tenaga kesehatan lain untuk mencapai tujuan yang telah ditetapka, digunakan sebagai pedoman dalam melakukan tindaan keperawatan yang sistematis dan efektif. Luaran keperawatan akan 
menjadi acuan bagi perawat dalam menetapkan kondisi atau status kesehatan seoptimal mungkin yang diharapkan dapat dicapai oleh klien setelah pemberian intervensi keperawatan (PPNI, 2019; Tajabadi et al., 2020). Perencanaan asuhan keperawatan gawat darurat berdasakan pengkajian primer sesuai dengan tabel 1 .

Perawat mengimplementasikan intervensi tindakan keperawatan yang telah diidentifikasi dalam rencana asuhan keperawatan gawat darurat untuk mencapai tujuan yang telah ditetapkan. Intervensi keperawatan merupakan segala bentuk terapi yang dikerjakan perawat yang didasarkan pada pengetahuan dan penilaian klinis untuk mencapai peningkatan, pencegahan, dan pemulihan kesehatan klien individu, keluarga, dan komunitas (PPNI, 2018). Penilaian perkembangan kondisi pasien stelah dilakukan tindakan keperawatan gawat darurat yang mengacu pada kriteria hasil yang termuat didalam SLKI. Hasil evalusi ini menggambarkan tingkat keberhasilan tindakan keperawatan gawat darurat (Alvarez et al., 2018).

\section{Mutu Pengembangan Format Dokumentasi Asuhan Keperawatan Gawat Darurat Berbasis SDKI, SLKI, dan SIKI}

Dokumentasi asuhan keperawatan merupakan suatu bentuk pelayanan kepada pasien secara tidak langsung yang pelaksanaannya mengikuti tahapan proses keperawatan yaitu pengkajian, diagnosis keperawatan, perencanaan, tindakan, dan evaluasi keperawatan yang disusun secara sistematis, valid, dan dapat dipertanggung jawabkan secara hukum dan moral (Akhu-Zaheya et al., 2018). Responden menyatakan bahwa format dokumentasi asuhan keperawatan gawat darurat berbasis SDKI, SLKI, dan SIKI yang diuji dapat berjalan sebagaimana mestinya. Format pengkajian asuhan keperawatan gawat darurat yang terdiri format pengkajian, penulisan diagnosis, intervensi, implementasi, dan evaluasi mudah digunakan. Lembar yang diujikan responden mengatakan banyak, namun tidak membingungkan, responden juga mengatakan bahwa komponen-komponen yang terdapat dalam format dokumentasi asuhan keperawatan perlu digabungkan sesuai dengan tabel 2 dan 3.

Mutu pelayanan keperawatan gawat darurat merupakan suatu indikator kinerja klinis pelayanan keperawatan gawat darurat dapat menjamin keselamatan, menurunkan angka kematian dan kecacatan serta meningkatkan kepuasan pasien. Kelengkapan komponen dokumentasi asuhan keperawatan telah memuat semua rangkaian proses keperawatan yang terdiri dari pengkajian primer, penentuan diagnosis, penentuan luaran, rencana intervensi, mengimplementasikan rencana intervensi yang sudah dibuat, dan mengevalusi keberhasilan penyelesaian masalah. Mutu pengembangan asuhan keperawatan gawat darurat sesuai dengan tabel 4.

Pelaksanaan dokumentasi asuhan keperawatan gawat darurat berbasis SDKI, SLKI, dan SIKI oleh perawat telah akurat, cermat, dan teliti dilaksanakan, yaitu menjalankan rangkaian proses asuhan keperawatan gawat gawat darurat, dimana rangkaian proses asuhan keperawatan telah mengacu pada penyelamatan nyawa dan meminimalisir adanya kecacatan yang terjadi pada pasien yang diakibatkan oleh penyakitnya. Dokumentasi asuhan keperawatan gawat darurat berbasis SDKI, SLKI, dan SIKI yang dituliskan sangat relevan dengan diagnosis medis pasien sehingga pelayanan keperawatan yang dijalankan sangat menopang diagnosis medis pasien, sehingga menjadi sebuah pelayanan kesehatan yang utuh dan komprehensif untuk penyelamatan nyawa dan meminimalisir adanya kecacatan yang terjadi pada pasien yang diakibatkan oleh penyakitnya. Dokumentasi asuhan keperawatan gawat darurat berbasis SDKI, SLKI, dan SIKI memenuhi unsur 
kebaruan, yang artinya adalah komponen-komponen dokumentasi asuhan keperawatan mempunyai sifat-sifat baru yang mengacu pada SDKI, SLKI, dan SIKI

\section{SIMPULAN}

Format dokumentasi asuhan keperawatan berbasis SDKI, SLKI, SIKI dapat digunakan di ruang gawat darurat untuk meningkatkan kualitas asuhan keperawatan.

\section{SARAN}

Saran bagi Rumah Sakit Dradjat Prawiranegara adalah format dokumentasi asuhan keperawatan berbasis SDKI, SLKI, dan SIKI di ruang gawat darurat akan dijadikan sebagai sumber referensi oleh komite keperawatan untuk megadakan perubahan format dokumentasi asuhan keperawatan di ruang gawat darurat.

\section{DAFTAR PUSTAKA}

Akhu-Zaheya, L., Al-Maaitah, R., \& Hani, B. S. (2018). Quality of Nursing Documentation: Paper-Based Health Records Versus Electronic-Based Health Records. Journal of Clinical Nursing, 27(3-4), e578-e589. https://doi.org/10.1111/jocn.14097

Alvarez, C., Rojas, E., Arias, M., Munoz-Gama, J., Sepúlveda, M., Herskovic, V., \& Capurro, D. (2018). Discovering Role Interaction Models in the Emergency Room Using Process Mining. Journal of Biomedical Informatics, 78(June 2017), 60-77. https://doi.org/10.1016/j.jbi.2017.12.015

Asmirajanti, M., Hamid, A. Y. S., \& Hariyati, R. T. S. (2019). Nursing Care Activities Based on Documentation. BMC Nursing, 18(Suppl 1), 1-5. https://doi.org/10.1186/s12912-019-0352-0

Bond, W. F., Kim, M., Franciskovich, C. M., Weinberg, J. E., Svendsen, J. D., Fehr, L. S., Funk, A., Sawicki, R., \& Asche, C. V. (2018). Advance Care Planning in an Accountable Care Organization Is Associated with Increased Advanced Directive Documentation and Decreased Costs. Journal of Palliative Medicine, 21(4), 489-502. https://doi.org/10.1089/jpm.2017.0566

Frink, M., Lechler, P., Debus, F., \& Ruchholtz, S. (2017). Multiple Trauma and Emergency Room Management. Deutsches Arzteblatt International, 114(29-30), 497-503. https://doi.org/10.3238/arztebl.2017.0497

Ioanna, P., Stiliani, K., \& Vasiliki, B. (2017). Nursing Documentation and Recording Systems of Nursing Care. Health Science Journal, 9(4), 71-79

Kamil, H., Rachmah, R., \& Wardani, E. (2018). What is the Problem with Nursing Documentation? Perspective of Indonesian Nurses. International Journal of Africa Nursing Sciences, 9, 111-114. https://doi.org/10.1016/j.ijans.2018.09.002

Kebede, M., Endris, Y., \& Zegeye, D. T. (2017). Nursing Care Documentation Practice: The Unfinished Task of Nursing Care in the University of Gondar Hospital. Informatics for Health and Social Care, 42(3), 290-302. https://doi.org/10.1080/17538157.2016.1252766

McCarthy, B., Fitzgerald, S., O’Shea, M., Condon, C., Hartnett-Collins, G., Clancy, M., Sheehy, A., Denieffe, S., Bergin, M., \& Savage, E. (2019). Electronic Nursing Documentation Interventions to Promote or Improve Patient Safety and Quality Care: A Systematic Review. Journal of Nursing Management, 27(3), 491-501. https://doi.org/10.1111/jonm.12727 
Permenkes No 47 Thn 2018 tentang Pelayanan Kegawat Daruratan, Pub. L. No. no 47 Thn 2018 (2018)

Pitcher, D., Fritz, Z., Wang, M., \& Spiller, J. A. (2017). Emergency Care and Resuscitation Plans. BMJ (Online), 356(February), 1-6. https://doi.org/10.1136/bmj.j876

Platts-Mills, T. F., Richmond, N. L., Lefebvre, E. M., Mangipudi, S. A., Hollowell, A. G., Travers, D., Biese, K., Hanson, L. C., \& Volandes, A. E. (2017). Availability of Advance Care Planning Documentation for Older Emergency Department Patients: A Cross-Sectional Study. Journal of Palliative Medicine, 20(1), 74-78. https://doi.org/10.1089/jpm.2016.0243

PPNI. (2017). Standar Diagnosis Keperawatan Indonesia (1st ed.). Dewan Pengurus Pusat Persatuan Perawat Nasional Indonesia

PPNI. (2018). Standar Intervensi Keperawatan Indonesia (1st ed.). Dewan Pengurus Pusat Persatuan Perawat Nasional Indonesia

PPNI. (2019). Standar Luaran Keperawatan Indonesia (1st ed.). Dewan Pengurus Pusat Persatuan Perawat Nasional Indonesia

Tajabadi, A., Ahmadi, F., Sadooghi Asl, A., \& Vaismoradi, M. (2020). Unsafe Nursing Documentation: A Qualitative Content Analysis. Nursing Ethics, 27(5), 1213-1224. https://doi.org/10.1177/0969733019871682

Vafaei, S. M., Manzari, Z. S., Heydari, A., Froutan, R., \& Farahani, L. A. (2018). Improving Nursing Care Documentation in Emergency Department: A Participatory Action Research Study in Iran. Open Access Macedonian Journal of Medical Sciences, 6(8), 1527-1532. https://doi.org/10.3889/oamjms.2018.303 